\title{
Numerical Analysis of Integrated Phase Change Material in Solar Water Heating Systems
}

\author{
Samuel Sami ${ }^{1}$, Orlando Copado ${ }^{2}$ \\ ${ }^{1}$ Research Center for Renewable Energy, Catholic University of Cuenca, Cuenca, Ecuador \\ ${ }^{2}$ Faculty of Engineering Energy, University Polytechnica de Sinaloa, Sinaloa, México \\ Email address: \\ dr.ssami@transpacenergy.com (S. Sami)
}

\section{To cite this article:}

Samuel Sami, Orlando Copado. Numerical Analysis of Integrated Phase Change Material in Solar Water Heating Systems. International Journal of Energy and Power Engineering. Vol. 5, No. 3, 2016, pp. 105-112. doi: 10.11648/j.jjepe.20160503.13

Received: May 5, 2016; Accepted: May 26, 2016; Published: June 6, 2016

\begin{abstract}
A mathematical model based upon the conservation and heat transfer equations has been developed to predict the thermal behavior of integrated phase change material in solar collector during thermal storage. The model includes fusion of the phase change material as well as sensible heat. The thermal behavior of the phase change material during charging and discharging have been studied numerically, and analyzed under different conditions. Comparisons were made against experimental data for validation of the predictive model. The model fairly predicted experimental data obtained at various inlet conditions.
\end{abstract}

Keywords: Phase Change Material, Thermal Storage, Solar Collector, Numerical Model, Simulation, Experimental Validation

\section{Introduction}

Interest in solar energy has increased as a result of environmental considerations and rational energy management. Thermal energy storage plays a significant role in practical and rational energy usage. Energy storage can be defined as the storage of energy that can later be utilized. The thermal energy can be stored as sensible, and latent, as well as thermochemical heat.

Excellent thermal properties such as high thermal storage capacity, good heat transfer rate between the heat storage material and heat transfer fluid and good stability to avoid chemical and mechanical degradation, are the key factors to viable solar thermal energy storage system [1-8]. Phase change materials (PCMs) can store/release a significant amount of heat during melting/solidification phase change processes. Paraffins are widely used as heat of fusion storage material due to their availability in a large temperature range [7].

A comparison of five commercial paraffin waxes as latent heat storage materials has been presented by Ukraincyk et al. [9]. The temperatures, heat capacities, of solid, and liquid paraffin waxes were measured by differential scanning calorimetry DCS. The thermal diffusivity was determined by utilizing the transient method. Experimental investigation was carried out by Khot [10] to understand the improvement of thermal storage system using water-PCM in comparison with water. The experiments were conducted for the same heat input during accelerated conditions in both Water-PCM and also water inside a thermal storage tank system. Lin et al. [11] reported on an experimental investigation of solar water heater with thermal storage. A study of an integrated paraffin wax phase change material in a flat plate solar collector was carried out. The PCM gave the highest performance when considering the day and night time efficiency compared to the case without PCM.

Thaib et al. [12] studied solar power system used to heat water for night time activities in rural areas with integrated paraffin wax in solar collectors. They reported that the efficiency of the solar collector increased by $36.6 \%$ with the use of paraffin wax. Senthilkumar et al. [13] conducted an investigation of solar water heater using phase change material embedded in the bottom of an absorber solar plate collector. During the off-sunshine hours, the phase change material releases heat to heat the water which results in higher efficiency of the solar collector.

The objective of this paper is to study the behaviour of phase change material integrated in solar plate collectors, to 
this end, a mathematical model for predicting the heat stored in integrated solar panel is presented. The model was established by integrating the energy conservation equations coupled with the heat transfer equations of the phase change material and heat transfer fluid. In the following sections, simulations of a thermal solar panel with integrated paraffin wax will be presented and analyzed. In addition, several experimental data are used to validate the proposed mathematical model. This model is intended, in particular, to study the effect of operating conditions such as solar radiation, working fluid flow rates, initial working fluid and paraffin wax temperatures on the phase change material and system performance as well as the thermal conversion efficiency of the integrated paraffin solar panel.

\section{Mathematical Model}

A schematic of the system under study is depicted in Fig. 1. The system consists of a thermal solar panel, thermal tank, and paraffin wax, piping and pump as well as control valves. The phase change material is paraffin wax. Paraffin is safe, reliable and environmentally sound. Paraffins are waxes at room temperature. Paraffin wax has good thermal energy storage density and low thermal conductivity. The paraffin was embedded in the solar panel and integrated into the heat exchanger in the solar panel as per Fig. 1 and 2. In order to write the energy conservation and heat transfer equations, the solar panel integrated paraffin wax heat exchanger was numerically divided into different elements as shown in Fig. 2 and 3. The proposed model is based on the following assumptions: PCM is homogeneous and isotropic, HTF is incompressible and it can be considered as a Newtonian fluid, inlet velocity and inlet temperature of the HTF are constant, PCM is in the solid phase for melting or in the liquid phase for solidification, thermophysical properties of the HTF and the PCM are constant. The phase change material experiences three phases; solid, liquid and mushy. The solid and liquid phases have sensible heat additions and the mushy has latent heat addition.

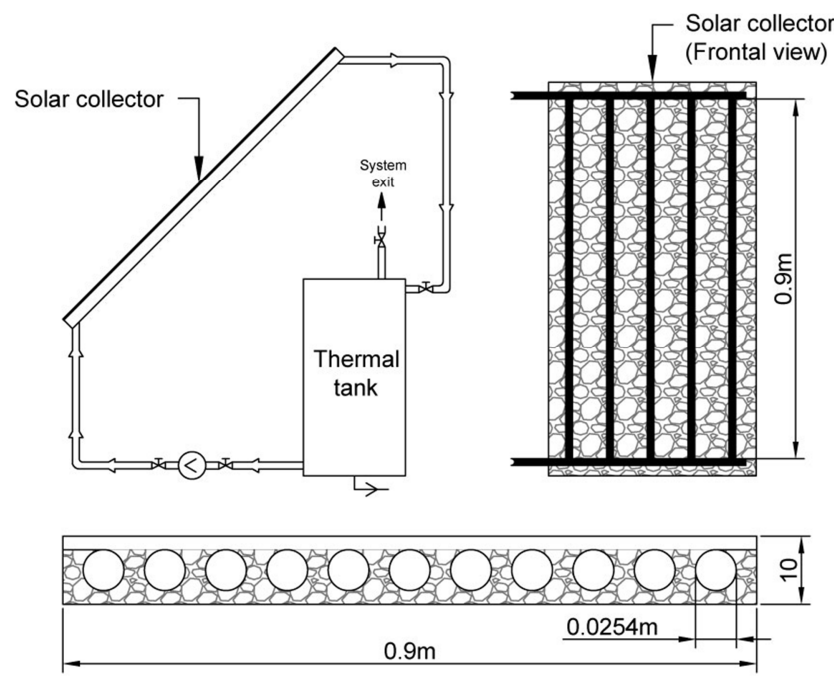

Fig. 1. Schematic of thermal solar panel system.

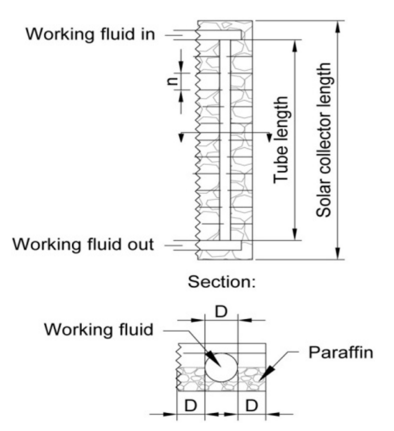

Fig. 2. Detailed of the solar panel heat exchanger single tube finite-difference formulation.

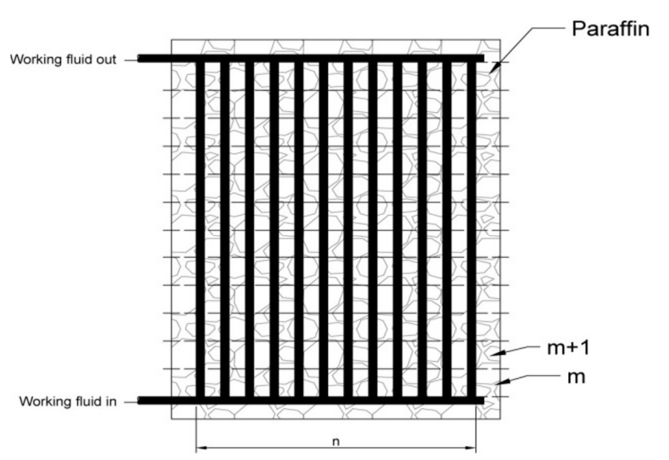

Fig. 3. Solar panel heat exchanger finite-difference formulation.

The conservation equations and heat transfer equations were written for each element as follows for each of the phases of from solid, mushy and liquid phases.

Energy conservation equation:

The heat released by the heat transfer fluid HTF by each tube can be written as follows, [14],

$$
\rho_{P C M} V_{P C M} C p_{P C M} \frac{\Delta T_{P C M}}{\Delta t}=Q t u b=m_{w} C p_{w} \Delta T_{w}
$$

$\Delta T_{w}$ : the heat transfer fluid temperature difference

$\Delta T_{P C M}$ : the phase change material temperature difference.

$Q t u b$, Heat per tubes $(\mathrm{kJ})$

The heat balance for the heat exchanger tube in the tank can be as follows [15];

$$
\left(T_{\text {in }}-T_{\text {out }}\right) C p_{w} m_{w}=2 \pi R \operatorname{lh}\left(T_{\text {in }}-T_{s f c}\right)
$$

Where the heat transfer coefficient is approximated as [15];

$$
\begin{aligned}
& h=\frac{K_{w}}{D_{H}} b_{2} R e^{n} \\
& R e=\frac{m_{w} D_{H}}{\mu A_{f}}
\end{aligned}
$$

Where:

$\Delta T_{P C M}$, Temperature different across PCM element $\left({ }^{\circ} \mathrm{C}\right)$

$\Delta t$, Time differential (s)

$\Delta T_{w}$, Temperature difference Water $\left({ }^{\circ} \mathrm{C}\right)$

$\mu$, viscosity $\left(\mathrm{m}^{2} / \mathrm{s}\right)$

And,

$R e$, Number-Reynolds

$$
R e=\frac{m_{w} D_{H}}{\mu A_{f}}
$$


Charge phase:

During the charging phase the water mass flow rate can be calculated from the heat released by the solar radiation,

Mass flow rate of water:

$$
m_{w}=\frac{G A_{\text {Panel }}}{1000 \times \cdot C p_{w} \cdot \Delta T_{w} \cdot n}
$$

Where:

$n$, number of tubes in solar panel

Equation (2) with the finite-difference formulation of the time derivative can be written for the solid phase as follows;

Solid phase:

$$
T_{P C M_{m+1}}=T_{P C M_{m}}+\frac{m_{w} C p_{w} \Delta T_{w}}{\rho_{s} V_{P C M} C p_{s}} \Delta t
$$

Where: $T_{P C M_{m}}$, Temperature of PCM at $m$ element $\left({ }^{\circ} \mathrm{C}\right)$ $m_{w}$, Water mass flow rate $\left(\frac{\mathrm{kg}}{\mathrm{s}}\right)$

$C p_{w}$, Specific heat of water $\left(\frac{k J}{k g K}\right)$

$V_{P C M}$, PCM volume $\left(\mathrm{m}^{3}\right)$

$C p_{s}$, PCM specific heat at solid phase $\left(\frac{k J}{k g K}\right)$

$\rho_{s}$, Density of PCM at solid phase $\left(\frac{\mathrm{kg}}{\mathrm{m}^{3}}\right)$

$G$, Radiation $\left(\frac{W}{m^{2}}\right)$

$R$, Tube radius $(m)$

$l$, Tube length $(m)$

$h$, Heat transfer coefficient

$b_{2} \& n$, Constants equal to 0.3 and 0.6 respectively

$D_{H}$, Hydraulic diameter $(m)$

$\mu$, Water viscosity $\left(\frac{m^{2}}{s}\right)$

$K_{w}$, Thermal conductivity of water $\left(\frac{k J}{m s^{\circ} \mathrm{C}}\right)$

$A_{\text {Panel }}$, Area of solar panel $\left(\mathrm{m}^{2}\right)$

$A_{f}$, Flow area $\left(m^{2}\right)$

$\mathrm{N}$ : number finite different element $(\mathrm{N}: 1-12)$

Same finite-difference formulation of the time derivative can be applied to the mushy and liquid phases as follows;

Mushy phase:

$$
\begin{aligned}
\gamma_{m+1} & =\gamma_{m}+\left(\frac{m_{w} C p_{w} \Delta T_{w, m u s h y}}{\rho_{L} V_{P C M} h_{L}}\right) \Delta t \\
Q t u b & =\rho_{L} V_{P C M} h_{L} \gamma \Delta t
\end{aligned}
$$

Where, $\gamma_{m}$, Liquid fraction at $m$ element (\%)

$h_{L}$, PCM latent heat $\left(\frac{\mathrm{kJ}}{\mathrm{kg}}\right)$

$V_{P C M}$, Volume of PCM $\left(\mathrm{m}^{3}\right)$

$\rho_{L}$, Density of PCM at liquid phase $\left(\frac{\mathrm{kg}}{\mathrm{m}^{3}}\right)$

$Q t u b$, Heat $(k J)$

Liquid phase:

With the finite-difference formulation of the time derivative, the PCM liquid temperature can be calculated as;

$$
T_{P C M_{m+1}}=T_{P C M_{m}}+\frac{m_{w} C p_{w} \Delta T_{w}}{\rho_{L} V_{P C M} C p_{L}} \Delta t
$$

Discharge phase:

During the discharge process phase change material experiences phase change from liquid to mushy and solid while yielding heat that is absorbed during the charging process. The water mass flow rate of heat transfer fluid during the discharge process can be calculated by;

$$
m_{w}=\frac{Q_{\text {Charging }}}{C p_{w} \cdot \Delta T_{w} \cdot n}
$$

Therefore, the total heat absorbed during the charging process by the phase change material during solid, mushy and liquid phases is:

$$
Q_{\text {Charging }}=m_{P C M}\left(C p_{s} \Delta T_{S}+h_{L}+C p_{L} \Delta T_{L}\right) \cdot n
$$

Where:

$\mathrm{m}_{\mathrm{pcm}}$ : mass of PCM per finite different element

\section{Numerical Procedure}

Equations (1) through (11) describing the energy conversion and heat transfer taking place during charging and discharging periods for phase change material, PCM, paraffin in a thermal solar panel have been solved as per the logical flow diagram shown in Fig. 4 where the input independent parameters are defined and other dependent parameters were calculated and integrated in the system of finite-difference equations. Iterations were performed until a solution is reached with acceptable iteration error.

The numerical procedure starts with using the solar radiation to calculate the mass flow water circulating in the solar panel. This is followed by using the finite difference formulation to predict the temperature profile of the phase change material and heat transfer fluid flow during the charging and discharging periods for the three phases; solid, mushy and liquid.

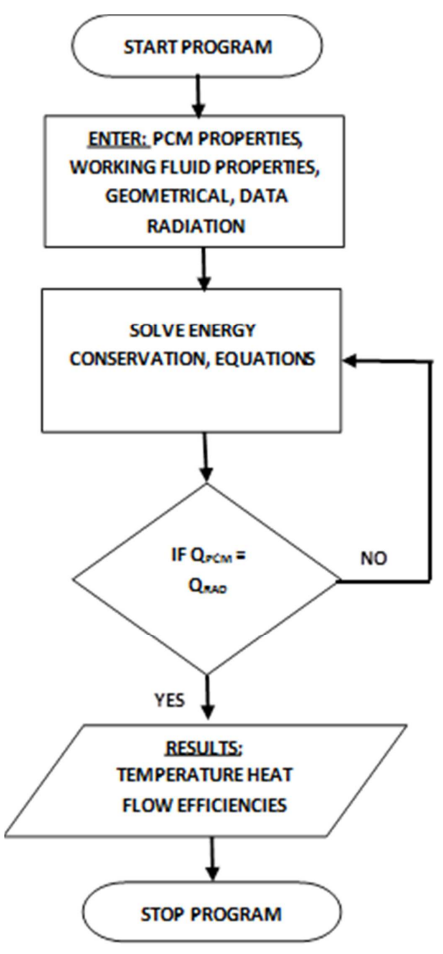

Fig. 4. Logical flow diagram for finite-difference scheme. 


\section{Discussion and Analysis}

The aforementioned system of equations (1) through (11) in finite-difference formulation has been numerically solved for different phase change materials (three paraffin waxes) and samples of the predicted results are plotted in Fig. 6 through 18 under different inlet conditions such as solar insolation, heat transfer fluid flow rates and heat transfer fluid temperatures. Specifications of each paraffin wax are given in Table 1. In general, it is quite clear from these figures that the temperature of paraffin wax increases during the charging process and decreases during the discharging. The rate of increase and decrease of the temperature depends on the thermodynamic and thermophysical properties of the paraffin wax, solar insolation and heat transfer between the heat transfer fluid and the paraffin wax material as well as initial conditions.

In the following sections, the impact of various aforementioned parameters will be presented and discussed. Tab. 1 includes properties of various paraffin waxes under investigation with different melting temperatures. In particular Fig. 5 presents the time variation of solar insolation $(\mathrm{W} / \mathrm{m} 2)$ measured at the site and employed in the simulation. It is quite clear that the intensity of radiation depends upon the hour of the day and the month of the year. The average values of radiation insolation were used in the present study. Fig. 6 presents the heat transfer profile between the paraffin wax PCM1 and the heat transfer fluid with solar radiation 550 $\mathrm{W} / \mathrm{m}^{2}$ during the charging process. The maximum temperature attained by paraffin wax during this process was $48^{\circ} \mathrm{C}$. The impact of solar radiation on the behaviour of paraffin during the charging process is illustrated

Table 1. Paraffin Wax Properties.

\begin{tabular}{ll}
\hline Paraffin PCM 1 [5] & Parameters \\
\hline Melting point & $46.7^{\circ} \mathrm{C}$ \\
Specific heat (solid) & $2.89 \mathrm{~kJ} / \mathrm{kgK}$ \\
Specific heat (liquid) & $2.89 \mathrm{~kJ} / \mathrm{kgK}$ \\
Density (Solid) & $947 \mathrm{~kg} / \mathrm{m}^{3}$ \\
Density (Liquid) & $750 \mathrm{~kg} / \mathrm{m}^{3}$ \\
Latent heat & $209 \mathrm{~kJ} / \mathrm{kg}$ \\
Paraffin PCM 2 [9] & \\
Melting point & $41^{\circ} \mathrm{C}$ \\
Specific heat (solid) & $2.48 \mathrm{~kJ} / \mathrm{kgK}$ \\
Specific heat (liquid) & $2.76 \mathrm{~kJ} / \mathrm{kgK}$ \\
Density (Solid) & $829 \mathrm{~kg} / \mathrm{m}^{3}$ \\
Density (Liquid) & $765 \mathrm{~kg} / \mathrm{m}^{3}$ \\
Latent heat & $288 \mathrm{~kJ} / \mathrm{kg}$ \\
Paraffin PCM 3 [9] & \\
Melting point & $37^{\circ} \mathrm{C}$ \\
Specific heat (solid) & $1.82 \mathrm{~kJ} / \mathrm{kgK}$ \\
Specific heat (liquid) & $2.17 \mathrm{~kJ} / \mathrm{kgK}$ \\
Density (Solid) & $911 \mathrm{~kg} / \mathrm{m}^{3}$ \\
Density (Liquid) & $799 \mathrm{~kg} / \mathrm{m}^{3}$ \\
Latent heat & $201 \mathrm{~kJ} / \mathrm{kg}$ \\
\hline
\end{tabular}

In Fig. 6. where, the paraffin wax temperature was plotted at various solar radiations; 550, 750 and $1000 \mathrm{~W} / \mathrm{m}^{2}$. The results showed that higher solar radiation received by the absorber plate leads to higher heat transfer fluid, water, temperature. However, less solar radiation intensity results in reducing the outlet water temperature. It is also quite evident from this figure that that the higher the solar radiation the higher the paraffin temperature. Similar behaviour has been observed in Fig. 7. through 11 for paraffin wax PCM 2 and PCM 3 [Tab. 1].

Fig. 11, 12 present the temperature profiles during discharging process for different paraffin waxes PCM 1, PCM 2 and PCM 3 with different melting points as outlined in Table1 and with different initial discharging temperatures. It is quite clear from this figure that the rate of heat transfer from the paraffin wax to the heat transfer fluid is dependent upon the thermophysical and thermodynamic properties of the paraffin wax. Also this figure clearly shows that the discharging time has a functional dependence upon the type of paraffin wax.

Furthermore, during the charging process of paraffin wax as presented in Fig. 13, the heat transferred from the paraffin wax to the heat transfer fluid is used to convert the liquid phase material into mushy and solid at the end of the discharging process. The total amount of heat transferred to the heat transfer fluid depends upon the condition of the paraffin wax and the heat transfer fluid thermal and thermophysical properties.

On the other hand, Fig. 14 illustrates that the discharging characteristics of paraffin wax depend upon the solar radiation used during the charging process and the higher the solar radiation the lower charging and consequently discharging time. Clearly, the results presented showed the required thermal energy to raise the water temperature that is influenced by solar radiation intensity.

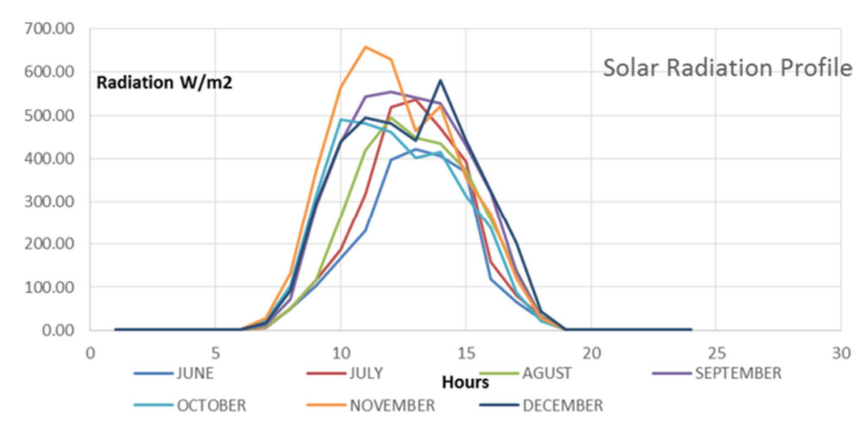

Fig. 5. Time variation of solar insolation measured horizontally during 2015.

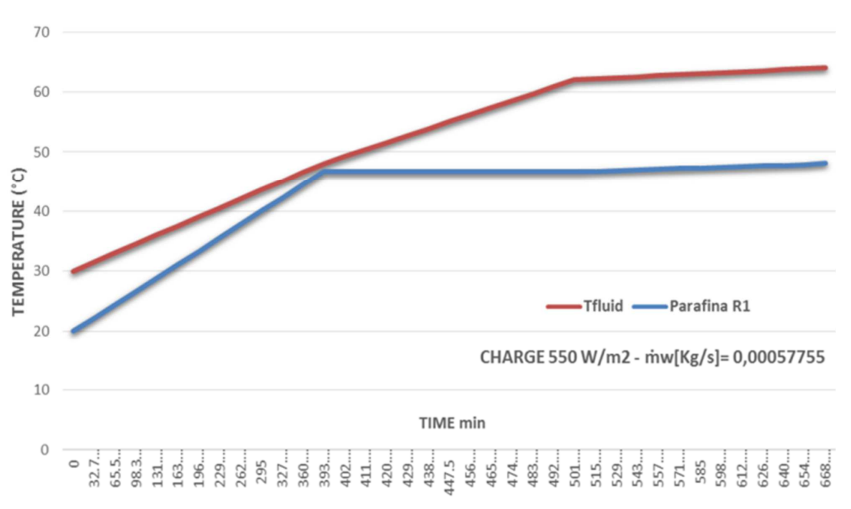

Fig. 6. Heat Transfer profile during charging process for paraffin wax PCMI [Tab. 1]. 
Furthermore, the water temperature is impacted by the amount of heat absorbed and released by the paraffin wax, Fig. 15 and 16 have been constructed to illustrate that effect, where the paraffin temperatures were plotted against the time to charge and discharge the paraffin wax at various solar radiations. It quite clear that higher solar radiation leads to higher paraffin wax temperatures and higher heat absorbed by the water and consequently the paraffin wax material.



Fig. 7. Paraffin wax PCM 1 [Tab. 1] temperature profile at different solar radiations.



Fig. 8. Variation of PCM 2 temperature [Tab. 1] during charging.

Obviously, the amount of heat absorbed that increases the temperature, depends mainly upon the solar radiation, and the thermal and thermophysical properties of the paraffin wax.

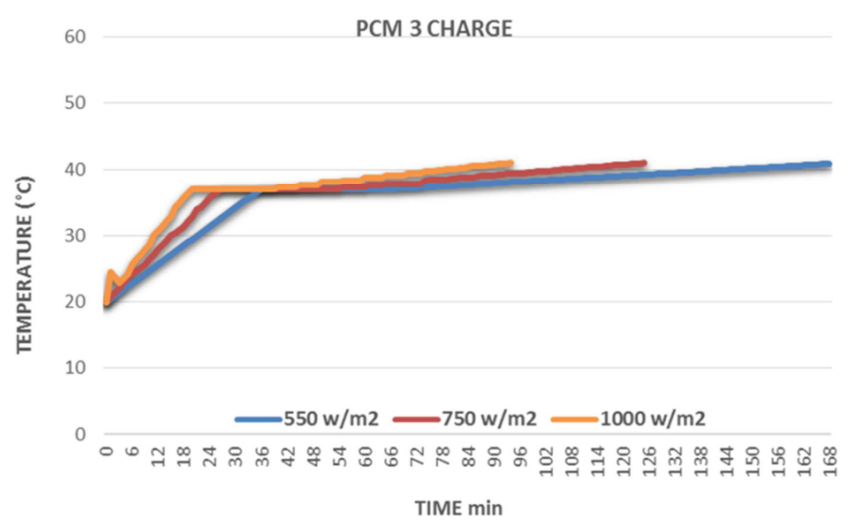

Fig. 9. PCM 3 [Tab. 1] Variation of working fluid temperature during charging.

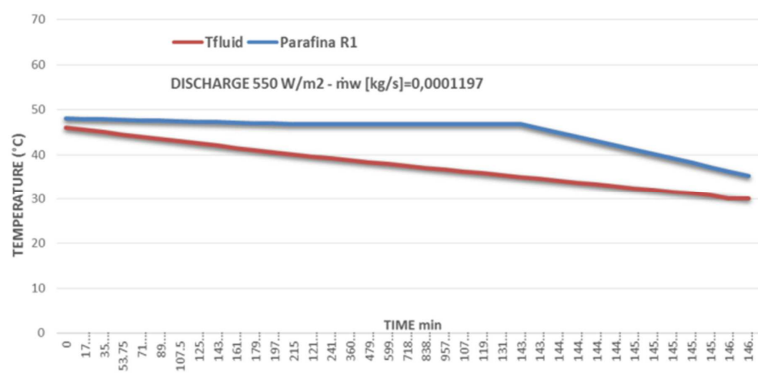

Fig. 10. Variation of temperature of working fluid and PCM 2 [Tab. 1] during discharging.

As illustrated in the previous figures, the amount of heat absorbed and its impact on the paraffin wax temperature is significantly influenced by the solar radiation and the water flow rate circulating in the solar collector heat exchanger. Therefore, figures 14 and 15 have been constructed to show the impact of the

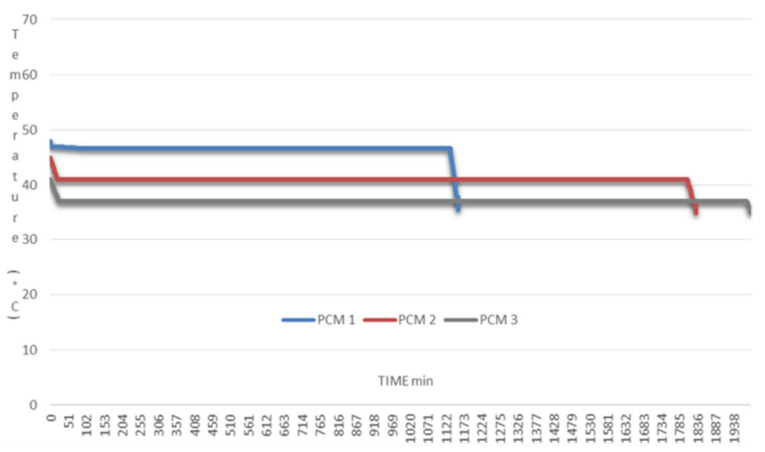

Fig. 11. Temperature profiles during discharging process for different paraffin wax [Tab. 1].

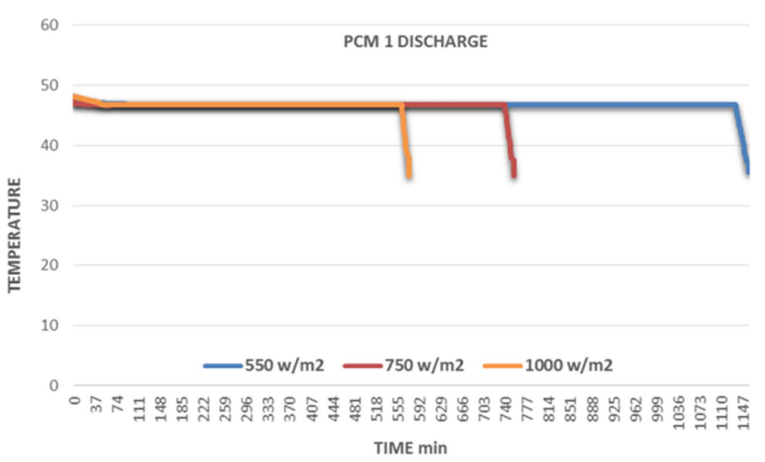

Fig. 12. Paraffin PCM1 [Tab. 1] temperatures profile during discharging process at different radiations.



Fig. 13. Heat absorbed profiles during charging process for different paraffin wax [Tab. 1]. 


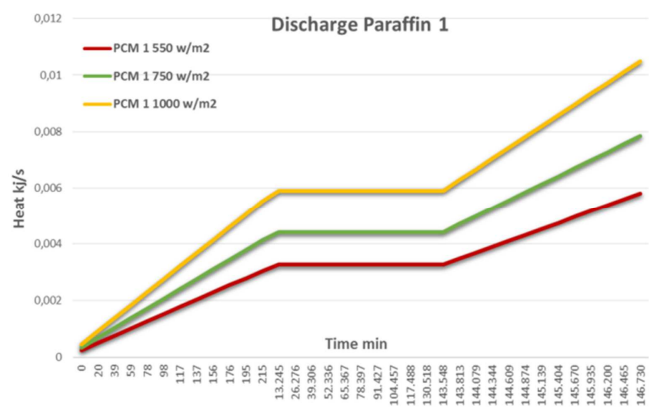

Fig. 14. Heat absorbed profiles during discharging process for different paraffin wax [Tab. 1].

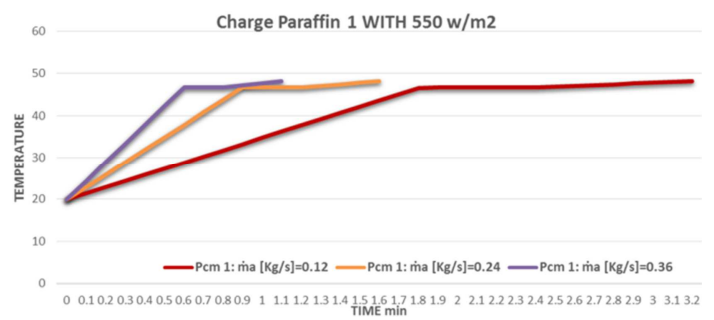

Fig. 15. Temperatures during charging process of PCM 1[Tab. 1] at different water flow rates.



Fig. 16. Temperatures during discharging process of PCM 1[Tab. 1] at different water flows

Paraffin wax temperature at various water flows. The figures show that higher water flow rate yields to higher paraffin wax temperature during the charging process. However, during the discharging process, the results presented in Fig. 16 illustrate that higher water flow rates result in low paraffin wax temperatures. Furthermore, Fig. 17 and 18 display the amount of heat absorbed by paraffin wax during the charging and discharging process at solar radiation 550 $\mathrm{W} / \mathrm{m}^{2}$. The results presented in these two figures show that the heat absorbed during the charging process increases at higher water mass flow rates and decreases at during discharging process at higher water mass flow rates. Similar behaviour has been observed for other paraffin waxes under study.



Fig. 17. Temperatures during discharging process of PCM 1[Table 1] at different water flow rates.

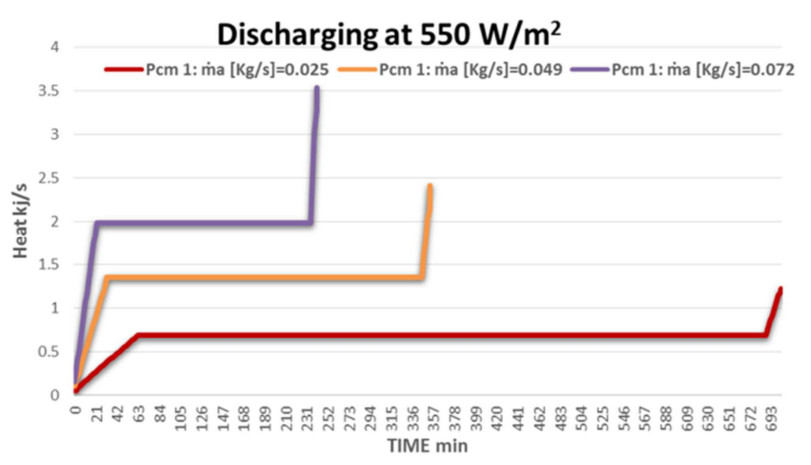

Fig. 18. Temperatures during discharging process of PCM 1[Tab. 1] at different water flow rates.

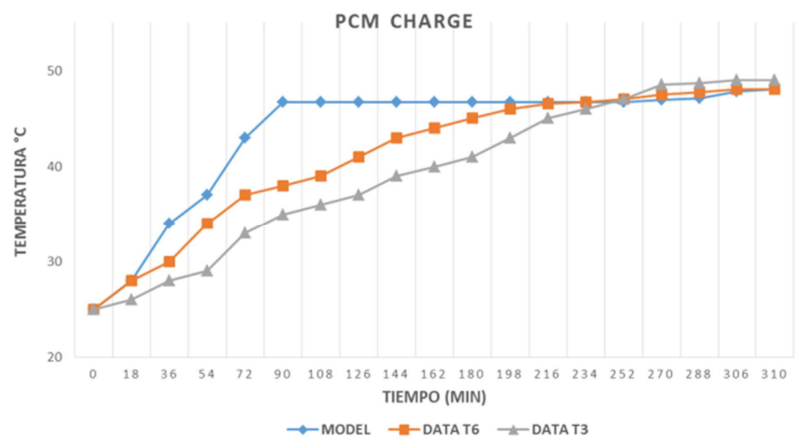

Fig. 19. Comparison of predicted results and data [12] during charging process.

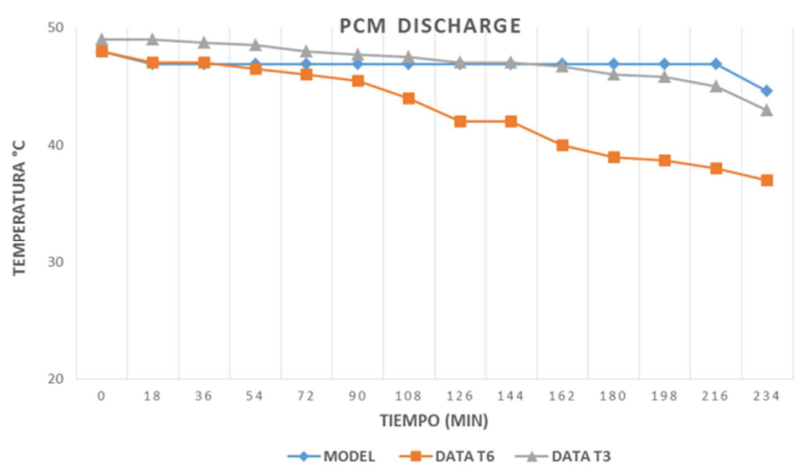

Fig. 20. Comparison of predicted results and data [12] during discharging process.

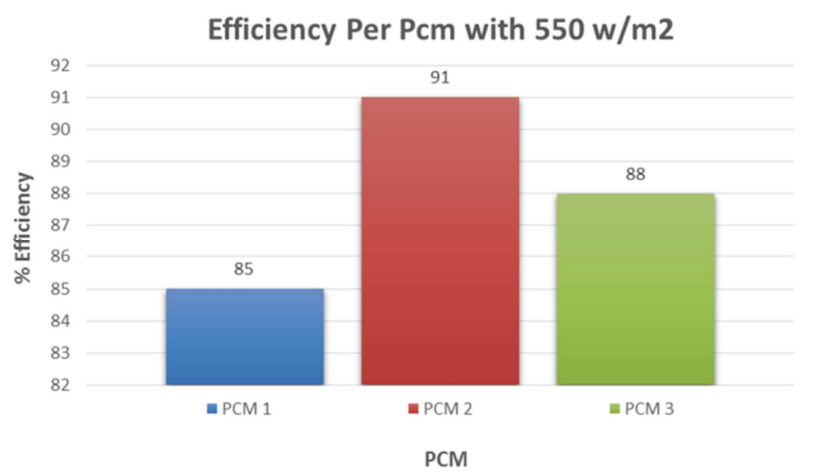

Fig. 21. Comparison of energy conversion efficiency of various paraffin waxes

Finally, in order to validate the model prediction, Fig. 19 and 20 have been constructed to compare the model prediction with data available in the literature. To our knowledge, the 
only data available on the integrated paraffin wax in solar plate collector is Thailb et al. reference [12]. His experimental investigation was conducted in open filed located at Syiah Kuala University. The water temperature, absorber plate (paraffin wax) and solar intensity radiation were measured and recorded every 10 minutes. The maximum temperature of hot water produced by solar collector equipped with paraffin was $70^{\circ} \mathrm{C}$. The predicted results were compared to the paraffin temperatures $\mathrm{T} 3$ and $\mathrm{T} 6$ recorded in the middle and end of the solar collector, respectively.

Furthermore, the data presented in Fig. 19 also showed that data stabilized after 90 minutes and the data and continued to be over-predicted. This was attributed to the fact that our model did not include heat losses along the collector heat exchanger and therefore, better prediction was obtained at the middle of the heat exchanger T3 compared to end of the heat exchanger T6. In addition, it can be observed that after 3 hours the heat transfer rate stabilized and the model was in fair agreement with data of T3 and T6. The numerical model's prediction showed that the phase change material was fully melted after 310 minutes since the charging cycle started. At this point, there was a fair agreement with the experimental data. Furthermore, Fig. 19 also showed that in general the model prediction of the total energy transferred to the paraffin wax material integrated in the solar collector was satisfactory, during the charging phase.

Similarly, the data displayed in Fig. 20 showed that during the discharging process the proposed model fairly predicted data in the middle T3 compared to the end of each heat exchanger tube T6. This is attributed to the fact that the cooling rate was faster and the effect of heat losses was small at the middle of the heat exchanger.

Finally, Fig. 21 has been constructed to compare the thermal storage energy conversion efficiencies of different paraffin waxes. In this figure the efficiencies of three paraffin waxes were presented; paraffin-1, paraffin-2 and paraffin-3 [Tab. 1]. The energy conversion efficiency is defined as the ratio between the discharge heat to the charging heat of paraffin wax. The results presented in this figure, clearly show that the higher the efficiency the lower the melting point and the ability to discharge more heat to the heat transfer fluid.

\section{Conclusions}

During the course of this study, the heat transfer characteristics of paraffin wax phase change material integrated in solar collector in a thermal storage process have been modeled, presented and analyzed as well as compared to experimental data at different inlet conditions. In general, the numerical model presented fairly predicted the heat transfer characteristics during phase change material and interactions between the heat transfer fluid and compared well with the experimental data.

The results presented also showed that the heat absorbed during the charging process increases at higher water mass flow rates and decreases at during discharging process at higher water mass flow rates. Similar behaviour has been observed for other paraffin waxes under investigation in this study.

\section{Nomenclature}

A $_{\text {Panel }}$ Area of solar panel $\left(\mathrm{m}^{\wedge} 2\right)$

$A_{f}$, Flow area $\left(m^{\wedge} 2\right)$

$\mathrm{C}_{\mathrm{ps}}$, PCM specific heat at solid phase $(\mathrm{kJ} /(\mathrm{kg} \mathrm{K}))$

$\mathrm{C}_{\mathrm{ps}}$, PCM specific heat at solid phase $(\mathrm{kJ} /(\mathrm{kg} \mathrm{K}))$

$\mathrm{C}_{\mathrm{pw}}$, Specific heat of water $(\mathrm{kJ} /(\mathrm{kg} \mathrm{K}))$

$\mathrm{D}_{\mathrm{H}}$, Hydraulic diameter $(\mathrm{m})$

$\mathrm{G}$, Radiation $\left(\mathrm{W} / \mathrm{m}^{\wedge} 2\right)$

$\mathrm{h}$, Heat transfer coefficient

$h_{L}$, PCM latent heat $\left(\frac{k J}{k g}\right)$

$\mathrm{K}_{\mathrm{w}}$, Thermal conductivity of water $\left(\mathrm{kJ} /\left(\mathrm{ms}^{\circ} \mathrm{C}\right)\right)$

1, Tube length (m)

$\mathrm{m}_{\mathrm{w}}$, Water mass flow rate $(\mathrm{kg} / \mathrm{s})$

$\mathrm{N}$ : number finite different element $(\mathrm{N}: 1-12)$

$Q t u b$, Heat $(k J)$

$\mathrm{R}$, Tube radius (m)

$\mathrm{T}_{\text {PCMm, }}$, Temperature of PCM at $\mathrm{m}$ element $\left({ }^{\circ} \mathrm{C}\right)$

$\mathrm{V}_{\text {PCM }}$, PCM volume $\left(\mathrm{m}^{3}\right)$

$V_{P C M}$, Volume of PCM $\left(\mathrm{m}^{3}\right)$

Greek

$\rho_{\mathrm{s}}$, Density of PCM at solid phase $\left(\mathrm{kg} / \mathrm{m}^{\wedge} 3\right)$

$\rho_{L}$, Density of PCM at liquid phase $\left(\frac{\mathrm{kg}}{\mathrm{m}^{3}}\right)$

$\mu$, Water viscosity $\left(\mathrm{m}^{\wedge} 2 / \mathrm{s}\right)$

$\gamma_{m}$, Liquid fraction at $m$ element (\%)

\section{Acknowledgement}

The research work presented in this paper was made possible through the support of the Catholic University of Cuenca.

\section{References}

[1] Y Tian, CY Zhao. A review of solar collectors and thermal energy storage in solar thermal applications. Applied Energy 104 (2013): 538-553.

[2] Farid M. M, Khudhair, A. M., Razack, S. A. and Al-Hallaj S. A review on phase change energy storage material. Energy Conversion and Management, 2004; 45: 1597.

[3] Elawadhi, E. M., Phase change process with free convection in a circular enclosure; numerical simulation. Computer \& Fluids, 2005; (33), 1335-148.

[4] Tardy F. and Sami S. M., (2008), An experimental study determining behaviour of heat pipes in thermal storage, International Journal of Ambient Energy, 2008; 29, (3).

[5] Razali T. Hamdani, Irwasnsyah, Zaini, (2004), Investigation of performance of solar water heater system using paraffin wax, ARPN Journal of Engineering and Applied Sciences, 2014; 9, (10).

[6] Thirugnanm, C, and Marimuthu, P (2013), Experimental analysis of latent heat thermal energy storage using paraffin wax as phase change material, International Journal of Engineering and Innovative Technology (IJEIT), 2013; 3, (2).

[7] Hale DV, Hoover M. J, O’Neill MJ. (1971), Phase change materials hand book. 
[8] Alabaa: Marshal Space Flight Center.

[9] Sami, S. M., F. Tardy"(2015), Numerical prediction of thermal storage using phase change material" IJIRE, Volume 3, No 4.

[10] Ukrainczyk N., Kurajica S., and Sipusic J., (2010), Thermophysical comparison of five commercial paraffin waxes as latent heat storage materials, Chem. Biochem. Eng. Q 24, (2), 129-137.

[11] Khot, S. A., (2014), Enhancement of thermal storage system using phase change material, Energy Procedia, 54, 142-151, 2014.

[12] Lin, S. C, Al-Kayiem, H. H. and Bin Aris, M., S., (2012), Experimental investigation on performance enhancement of integrated PCM-Flat solar collector, Journal of Applied Sciences, 12 (23), 2390-2396, 2012.
[13] Thaib, R, Hamdani, and Irwansyah, and Zaini (2014), Investigation of performances of solar water heater system using paraffin wax, ARPN Journal of Engineering and Applied Sciences, vol. 9, No. 10, Pp. 1749-52, 2014.

[14] Senthilkumar, R, Sithivinanayagam, N, and Shankar, N, (2014), Experimental investigation of solar water heater using phase change material, International Journal of Research in Invent Technology, Vol. 2, No. 7, July 2014.

[15] [14] Milisic, E, (2013), Modeling of energy storage using phase-change materials (PCM materials), Master thesis, Norwegian University of Science and Technology, July 2013.

[16] Mahmus, A, Sopian, K, Alghoul, M. A. and Sohif, M, (2009), Using a paraffin wax-aluminum compound thermal storage material in solar air heater, ARPN Journal of Engineering and Applied Sciences, Vol. 4, No. 10, pp. 74-77, Dec 2009. 